\title{
Effect of Azadirachta indica flower extract on functional recovery of sciatic nerve crush injury in rat models of DM
}

\author{
NAPATR SRIRAKSA ${ }^{1}$, RATCHANIPORN KONGSUI $^{1}$, SITTHISAK THONGRONG $^{2}$, \\ ACHARAPORN DUANGJAI $^{1}$ and THANEEYA HAWISET ${ }^{3}$
}

\begin{abstract}
Divisions of ${ }^{1}$ Physiology and ${ }^{2}$ Anatomy, School of Medical Sciences, University of Phayao, Mueang, Phayao 56000;
${ }^{3}$ School of Medicine, Mae Fah Luang University, Mueang, Chiang Rai 57100, Thailand
\end{abstract}

Received April 30, 2018; Accepted October 26, 2018

DOI: $10.3892 /$ etm.2018.6931

\begin{abstract}
Chronic hyperglycemia causes nerves to be more susceptible to compression, which often occurs as a result of hyperglycemia-induced oxidative stress. Oxidative stress impairs nerve function and delays nerve recovery. Azadirachta indica, a herb from Thailand, possesses antioxidant and antidiabetic properties. The aim of the present study was therefore to investigate the effect of $A$. indica flower extract on the functional recovery of a sciatic nerve crush injury in rat models of diabetes mellitus (DM). Male Wistar rats were randomly assigned into seven groups including the control rats, rats with DM subjected to sham surgery and treated with vehicle, and rats with DM subjected to the crush surgery and treated with vehicle or A. indica flower extract at a dose of 250,500 or $750 \mathrm{mg} / \mathrm{kg}$ animal body weight, or with vitamin C. DM was induced using a single intraperitoneal injection of streptozotocin (55 mg/kg animal body weight). Rats subjected to a sciatic nerve crush injury or sham surgery were orally treated with either vehicle, A. indica flower extract or vitamin $\mathrm{C}$ for 21 days. Functional recovery was assessed every 3 days using a walking track analysis, foot withdrawal reflex test and rotarod test. At the end of the study, the rats were sacrificed and their left sciatic nerves were harvested in order to determine malondialdehyde levels, superoxide dismutase activity and axon density. The treatment with A. indica flower extract significantly improved functional recovery, especially motor and sensory functions. The extract significantly decreased malondialdehyde levels, and increased superoxide dismutase activity and axon density. The results of
\end{abstract}

Correspondence to: Dr Napatr Sriraksa, Division of Physiology, School of Medical Sciences, University of Phayao, 19 Moo 2 Phahonyothin Road, Mueang, Phayao 56000, Thailand

E-mail: napatr.sri@gmail.com

Abbreviations: DM, diabetes mellitus; STZ, streptozotocin; MDA, malondialdehyde; SOD, superoxide dismutase; SFI, sciatic function index; PWL, paw withdrawal latency

Key words: Azadirachta indica, crush injury, diabetes mellitus, functional recovery, sciatic nerve the current study indicate that the mechanism underlying the enhanced functional recovery of the sciatic nerve following treatment with $A$. indica flower extract may be associated with an antioxidative effect. However, further studies are required to confirm the current results.

\section{Introduction}

In recent years, the number of cases of diabetes mellitus (DM) in Thailand has been rapidly increasing and the prevalence of DM per 100,000 individuals increased from 1,032.50 in 2014 to $1,292.79$ in 2016 (1). Diabetes causes numerous severe complications, including pain and sensory and movement disorders. These complications negatively affect the quality of life of individuals and impose a socio-economic burden on the society (2). Nerve compression syndrome, also known as entrapment neuropathy, is a type of diabetic neuropathy commonly identified among patients with diabetes (3). Pain and inflammation associated with the nerve compression syndrome may be alleviated by local steroid injection; however, this injection can cause adverse side effects predominantly for bones and skin, including skin depigmentation, skin atrophy and a decrease in bone mineral density $(4,5)$. Surgery to remove the compression is a more permanent treatment option; nevertheless, full decompression and complete functional recovery are not always attainable (6). Therefore, alternative treatment methods, including administration of medicinal herbs, may benefit both patients and the society.

DM frequently leads to long-term hyperglycemia, which alters the neurochemical pathways in the nerves and increases the susceptibility to compression (7). Numerous possible explanations for this increased susceptibility to nerve compression have been proposed. It has been hypothesized that excessive glucose is reduced to sorbitol in the polyol pathway, and subsequently, sorbitol promotes nerve swelling due to its low plasma permeability, and may promote osmosis (8). The second possible explanation is that hyperglycemia induces the production of advanced glycation end-products (AGEs) (9). AGEs may impair the vascular supply to the nerve tissues, including nerve fibers, Schwann cells and endothelial cells of vasa nervosum, and consequently, promote the destruction of the nerve fibers $(10,11)$. The third possible explanation is that glucose overload may induce an increased activity of 
electron transport chain due to nerve axons being rich in mitochondria (12). The excessive of production free radicals may subsequently cause oxidative damage to DNA, proteins and lipids (13). It has been previously demonstrated that antioxidants serve an important role in the prevention of cell damage against reactive oxygen species (14). Therefore, the identification of a plant exhibiting both antioxidative and hypoglycemic properties would be beneficial for the treatment of patients with diabetes. Numerous studies have reported that plants containing antioxidants could promote nerve recovery following a crush injury (15-17).

Azadirachta indica A. Juss. var. siamensis Valeton (A. indica), also known as Sadao in Thailand, is a member of the Meliaceae family (18). The edible parts of $A$. indica are young leaves and young flowers (19). A. indica is considered a safe medicinal plant and previous studies indicated that it exhibits antioxidative (20), anti-inflammatory (21), antiulcerative (22), and anticancer effects (23). Furthermore, A. indica has been demonstrated to exhibit antidiabetic properties (24). Specifically, the current study hypothesizes that $A$. indica has the potential to reduce oxidative stress in a diabetic condition and potentially to promote nerve recovery. However, the effect of $A$. indica flower extract on the functional recovery of sciatic nerve crush injury in diabetic rats remains to be elucidated.

\section{Materials and methods}

Plant material and extract preparation. A. indica flowers were collected from Maetumboonyong, Mueang, Phayao, Thailand during December 2015 to January 2016. The voucher specimen (no. 003805) was deposited in the herbarium of the Faculty of Biology, Naresuan University, Mueang, Phitsanulok, Thailand. The sample was authenticated by Dr Pranee Nangngam, the Faculty of Biology, Naresuan University, Mueang, Phitsanulok, Thailand. The flowers were washed and blended with distilled water (plant to water ratio, 1:3). A powdered extract was obtained after this solution was filtered and freeze-dried. The powder extract was stored at $-20^{\circ} \mathrm{C}$ until further use.

Animals. A total of 52 eight-week old male Wistar rats (weight, 200-220 g) were obtained from the Nomura Siam International Co., Ltd. (Bangkok, Thailand). During the experimental procedure, 3 rats were housed per cage and maintained under a 12-h light/dark cycle with food and water ad libitum. The rats were randomly divided into seven groups including: i) Group 1, untreated rats not subjected to surgery $(n=8)$; ii) group 2, rat models of DM with sham surgery administered distilled water $(n=5)$; iii) group 3 , rat models of DM with sciatic nerve crush surgery administered distilled water $(n=8)$; iv) group 4, rat models of DM with sciatic nerve crush surgery administered $A$. indica extract at a dose of $250 \mathrm{mg} / \mathrm{kg}$ animal body weight $(\mathrm{BW} ; \mathrm{n}=8)$; v) group 5 , rat models of DM with sciatic nerve crush surgery administered $A$. indica extract at a dose of $500 \mathrm{mg} / \mathrm{kg}(\mathrm{n}=8)$; vi) group 6 , rat models of DM with sciatic nerve crush surgery administered $A$. indica extract at a dose of $750 \mathrm{mg} / \mathrm{kg}(\mathrm{n}=8)$; and vii) group 7, rat models of DM with sciatic nerve crush surgery administered vitamin $\mathrm{C}$ (Chem-Supply, Gillman, South Australia, Australia) at a dose of $100 \mathrm{mg} / \mathrm{kg} \mathrm{BW}(\mathrm{n}=7)$. The rats in groups $2-7$ were administered either vehicle (distilled water), $A$. indica flower extract or vitamin $\mathrm{C}$ once daily for 21 consecutive days following the sham operation or sciatic nerve crush surgery. At the end of the experiment, rats were euthanized with an overdose of sodium pentobarbital (intraperitoneal injection at dose of $100 \mathrm{mg} / \mathrm{kg}$ animal BW). Subsequently, left sciatic nerves were collected and half of each nerve was used to determine the malondialdehyde (MDA) levels and activity of superoxide dismutase (SOD). The other half of each nerve was used for histological analysis (axon density).

DM induction and sciatic nerve crush injury. DM was induced by a single intraperitoneal injection of streptozotocin (STZ) (Sigma-Aldrich; Merck KGaA, Darmstadt, Germany) at dose of $55 \mathrm{mg} / \mathrm{kg}$ animal BW. The fasting blood glucose level was assessed $72 \mathrm{~h}$ after the injection. The rats with plasma glucose levels of $\geq 250 \mathrm{mg} / \mathrm{dl}$ were regarded as diabetic rats and were enrolled for further surgery. A sciatic nerve crush surgery was performed following anesthesia using intraperitoneal injection of sodium pentobarbital (50 mg/ $\mathrm{kg}$ animal BW). An incision was made on the posterior left thigh and the sciatic nerve was carefully exposed at a point immediately distal to the gluteus maximus muscle. The nerve was crushed at a distance of $5 \mathrm{~mm}$ from the sciatic notch (midthigh) for $30 \mathrm{sec}$ using hemostatic forceps. The sham rats received the same surgery without a nerve crushing injury. To minimize the variability in the experimental process, each surgery was performed by the same person.

Walking trackanalysis. As previously described by Bain et al(25), the current study analyzed the sciatic function index (SFI) from the walking track analysis of the rats. Prior to the surgery, the rats were given five trials of walking on conventional paper. Recovery was assessed on day 3, 6, 9, 12, 15, 18 and 21 after surgery using one walking trial. Briefly, the rats were held by the chest and their hind feet were pressed down onto a stamp pad soaked with water-soluble black ink. The rats subsequently walked down a confined walkway (width, $21 \mathrm{~cm}$; length, $120 \mathrm{~cm}$ ) with a dark shelter at the end of the corridor to encourage movement such that inked footprints were left on the paper. The following measurements were subsequently taken: i) The distance from the heel to the third toe defined as the print length (PL); ii) the distance from the first to fifth toe defined as toe spread (TS); and iii) the distance from the second to the fourth toe defined as the intermediate toe spread (ITS). The SFI value of each group was calculated using the Bain formula (25): SFI $=(-38.3 \times$ PLF $)+$ $(109.5 \times$ TSF $)+(13.3 \times$ ITF $)-8.8$, where PLF (print length factor $)=($ experimental PL-normal PL)/normal PL; TSF (toe spread factor $)=($ experimental TS-normal TS $) /$ normal TS; ITF (intermediate toe spread factor $)=($ experimental ITS - normal ITS)/normal ITS. An SFI value close to 0 indicates normal function. In the present study however, SFI values between (-10)-(10) were considered to be within the normal range (16).

Foot withdrawal reflex. A modified version of the hot plate test was used to determine the functional sensory recovery of the rats on day 3, 6, 9, 12, 15, 18 and 21 after surgery (26). Prior to each testing session, the rats were acclimatized to the non-heated plate for $10 \mathrm{~min}$. Subsequently, the time it took the rat to remove its paw from a hot plate $\left[50^{\circ} \mathrm{C}, 5^{\circ} \mathrm{C}\right.$ lower than in the original study by Menéndez et al (26)] was recorded 
and defined as the paw withdrawal latency (PWL). No rat was allowed to remain in contact with the heated plate for $>20$ sec. PWL was measured with the left paw three times and the mean was subsequently calculated. The time interval between sessions was 5 min.

Rotarod test. A rotarod apparatus model Acceler Rota-Rod (Jones \& Roberts) for rats 7750 (Comerio, VA, Italy) was used to determine sensorimotor coordination of the rats. The apparatus was provided by the Division of Neuroanatomy, Department of Anatomy Histology and Embryology, Medical University Innsbruck, Innsbruck, Austria. All rats underwent a 7-day training program. Rats were trained to walk against the motion of the rotating drum at a constant speed of $10 \mathrm{rpm}$ for a maximum of $1 \mathrm{~min}$. If a rat fell off the rod during a training trial, it was put back on the rotating drum. Each rat received four training trials per day with an interval trial time of $10 \mathrm{~min}$. Although the accelerating mode was more suitable to evaluate the sensorimotor coordination of rats $(15,27)$, the poor motor function of the rats of the present study following surgery prevented the use of that specific mode. A previous study by Abada et al (28) demonstrated that the best rotarod performance of rats is achieved when the speed used on the test day is faster than that on the training days. This is due to rats having already learnt how to climb using a constant speed $(10 \mathrm{rpm})$. Therefore, the speed of the rotarod was set to a constant speed of $12 \mathrm{rpm}$ for the test. The amount of time that the rat remained on the rotating drum was recorded for three trials and the values were averaged to obtain a falling latency. The maximum allowed duration was $30 \mathrm{sec}$. The apparatus was sprayed with a $70 \%$ ethanol solution between sessions and wiped with tissue paper.

Homogenate preparation. The left sciatic nerve was isolated from each rat at the end of the experiment. Homogenate was prepared in $1 \mathrm{ml}$ of $0.1 \mathrm{M}$ phosphate buffer ( $\mathrm{pH} 7.4$ ). The obtained nerve homogenate was adjusted to $10 \% \mathrm{w} / \mathrm{v}$ and centrifuged at $10,000 \mathrm{x} \mathrm{g}$ and $4^{\circ} \mathrm{C}$ for $1 \mathrm{~h}$ using a microcentrifuge (1-15PK; Sigma Laborzentrifugen GmbH; Osterode am Harz, Germany). The supernatant was harvested and processed for the estimation of biochemical parameters.

Determination of MDA levels. As previously described by Ohkawa et al (29), the level of MDA was assessed using thiobarbituric acid reactive substances. Briefly, $100 \mu 1$ of nerve homogenate solution, $100 \mu \mathrm{l}$ of $8.1 \%$ (w/v) sodium dodecyl sulfate, $750 \mu \mathrm{l}$ of $20 \%(\mathrm{v} / \mathrm{v})$ acetic acid ( $\mathrm{pH} 3.5)$ and $750 \mu \mathrm{l}$ of $0.8 \%(\mathrm{w} / \mathrm{v})$ thiobarbituric acid (all from Sigma-Aldrich; Merck $\mathrm{KGaA}$ ) were mixed thoroughly and boiled in a water bath at $95^{\circ} \mathrm{C}$ for $1 \mathrm{~h}$ then cooled immediately under running tap water. After cooling, $500 \mu \mathrm{l}$ of chilled water and $2.5 \mathrm{ml}$ of a mixture of butanol and pyridine (15:1 v/v; each Sigma-Aldrich; Merck KGaA) were added into each sample and mixed well. The solution was subsequently centrifuged at $800 \mathrm{x} \mathrm{g}$ and $4^{\circ} \mathrm{C}$ for $20 \mathrm{~min}$. The upper pink layer was harvested and the absorbance was measured at a wavelength of $532 \mathrm{~nm}$ using a spectrophotometer (GENESYS ${ }^{\text {TM }}$ 20; Thermo Fisher Scientific, Inc., Waltham, MA, USA). 1,1,3,3-Tetramethoxypropane (Sigma-Aldrich; Merck KGaA) was used as a standard MDA. The level of MDA was expressed in nmol/mg protein.
Determination of SOD activity. SOD activity was determined via a nitroblue tetrazolium reduction assay, as previously described (30). The xanthine-xanthine oxidase system was used as a superoxide generator. Briefly, a reaction mixture containing $20 \mu \mathrm{l}$ of nerve homogenate solution and $200 \mu \mathrm{l}$ of reaction mixture consisting of $57 \mathrm{mM}$ phosphate buffer solution $\left(\mathrm{KH}_{2} \mathrm{PO}_{4}\right), 0.1 \mathrm{mM}$ EDTA, $10 \mathrm{mM}$ cytochrome $\mathrm{C}$ solution, $50 \mu \mathrm{M}$ of xanthine solution and $20 \mu \mathrm{l}$ of xanthine oxidase solution $(0.90 \mathrm{mU} / \mathrm{ml})$ was prepared at $25^{\circ} \mathrm{C}$ for 5 min. All aforementioned reagents were from Sigma-Aldrich; Merck KGaA. The absorbance was measured at a wavelength of $415 \mathrm{~nm}$ with an ultraviolet-spectrophotometer (Biochrom 4060; Pharmacia Biotech, Uppsala, Sweden). A system devoid of xanthine oxidase served as the control and the three parallel experiments were conducted. SOD activity was expressed in $\mathrm{U} / \mathrm{mg}$ protein.

Histological assessment. The left sciatic nerve was collected from each rat at the end of the experiment. Half of each nerve was fixed in $4 \%$ paraformaldehyde at $4^{\circ} \mathrm{C}$ for $48 \mathrm{~h}$ and processed for paraffin embedding. Sections (5- $\mu \mathrm{m}$-thick) were cut using a microtome and stained with hematoxylin for $8 \mathrm{~min}$ and eosin for $1 \mathrm{~min}(\mathrm{H} \& \mathrm{E})$ at room temperature. A light microscope was subsequently used to examine the morphology of the axon for each nerve. The axon density was determined using the Image J software version 1.51 (National Institutes of Health, Bethesda, MD, USA) at a x20 magnification.

Statistical analysis. All data are presented as the mean \pm standard error of the mean. Statistical analysis was performed using one-way analysis of variance followed by LSD post hoc test for multiple comparisons. $\mathrm{P}<0.05$ was considered to indicate a statistically significant difference.

\section{Results}

Effect of $A$. indica flower extract on motor functional recovery. The effect of $A$. indica flower extract on SFI is presented in Table I. According to a previous study, normal walking pattern SFI can range between -10 and 10 (16). Before the crush injury, rats in all groups exhibited normal SFI. After the crush injury, rats underwent functional testing every 3 days. The rats with DM subjected to a sciatic nerve crush injury had a significantly lower SFI compared with rats in the control group $(\mathrm{P}<0.001)$ and rats with $\mathrm{DM}$ subjected to sham surgery $(\mathrm{P}<0.001)$. These differences indicated abnormal walking patterns among rats with nerve crush injury. Compared with the vehicle-treated group subjected to crush injury, administration of A. indica flower extract at a high dose $(750 \mathrm{mg} / \mathrm{kg}$ animal BW) significantly increased SFI on postoperative day 18 and 21 ( $\mathrm{P}<0.05$ and $\mathrm{P}<0.001$, respectively). Administration of A. indica flower extract at the medium dose $(500 \mathrm{mg} / \mathrm{kg}$ animal BW) significantly increased SFI on day 21 compared with the rats subjected to crush injury and treated with vehicle $(\mathrm{P}<0.01)$. Furthermore, administration of vitamin $\mathrm{C}$ significantly increased SFI on days 18 and 21 compared with the rats with crush injury treated with vehicle $(\mathrm{P}<0.05$ and $\mathrm{P}<0.01$, respectively). However, the SFI values on day 21 were between -20 and -40 , and, therefore, the SFI did not return to normal following treatment with $A$. indica flower extract or vitamin $\mathrm{C}$. 
Table I. Effect of A. indica flower extract on SFI.

\begin{tabular}{|c|c|c|c|c|}
\hline \multirow[b]{2}{*}{ Group } & \multicolumn{4}{|c|}{ SFI } \\
\hline & Baseline & Day 3 & Day 18 & Day 21 \\
\hline Control & $-4.24 \pm 2.67$ & $-8.68 \pm 1.44$ & $-8.75 \pm 1.25$ & $-8.30 \pm 1.21$ \\
\hline $\mathrm{DM}+$ sham + vehicle & $-8.00 \pm 1.09$ & $-11.45 \pm 1.64$ & $-3.69 \pm 3.82$ & $-5.00 \pm 1.75$ \\
\hline $\mathrm{DM}+$ crush + vehicle & $-4.98 \pm 1.70$ & $-69.42 \pm 1.57^{\mathrm{c}, \mathrm{d}}$ & $-55.40 \pm 4.86^{\mathrm{c}, \mathrm{d}}$ & $-43.70 \pm 2.41^{\mathrm{c}}$ \\
\hline $\mathrm{DM}+$ crush $+A \cdot$ indica 250 & $-7.90 \pm 1.59$ & $-68.07 \pm 2.94^{\mathrm{c}, \mathrm{d}}$ & $-46.69 \pm 2.32^{\mathrm{c}, \mathrm{d}}$ & $-39.02 \pm 1.88^{c}$ \\
\hline $\mathrm{DM}+$ crush $+A$. indica 500 & $-4.15 \pm 1.75$ & $-69.46 \pm 2.43^{\mathrm{c}, \mathrm{d}}$ & $-40.93 \pm 7.03^{\mathrm{b}, \mathrm{d}}$ & $-30.40 \pm 5.20^{\mathrm{c}, \mathrm{d}, \mathrm{f}}$ \\
\hline $\mathrm{DM}+$ crush $+A$. indica 750 & $-4.26 \pm 1.33$ & $-66.66 \pm 0.98^{\mathrm{c}, \mathrm{d}}$ & $-37.33 \pm 7.47^{\mathrm{b}, \mathrm{d}, \mathrm{e}}$ & $-22.44 \pm 2.32^{\mathrm{b}, \mathrm{d}, \mathrm{g}}$ \\
\hline $\mathrm{DM}+$ crush + Vit $\mathrm{C}$ & $-4.88 \pm 1.87$ & $-68.33 \pm 2.25^{\mathrm{cd}}$ & $-31.47 \pm 11.86^{\mathrm{a}, \mathrm{d}, \mathrm{e}}$ & $-28.97 \pm 4.09^{\mathrm{c}, \mathrm{d}, \mathrm{f}}$ \\
\hline \multicolumn{5}{|c|}{$\begin{array}{l}\text { Values are presented as the mean } \pm \text { standard error of the mean. }{ }^{\mathrm{a}} \mathrm{P}<0.05,{ }^{\mathrm{b}} \mathrm{P}<0.01 \text { and }{ }^{\mathrm{c}} \mathrm{P}<0.001 \mathrm{vs} \text {. the control; }{ }^{\mathrm{d}} \mathrm{P}<0.001 \mathrm{vs} \text {. the } \mathrm{DM}+\mathrm{sham}+\mathrm{vehicle} \\
\text { group; }{ }^{\mathrm{P}} \mathrm{P}<0.05,{ }^{\mathrm{f}} \mathrm{P}<0.01 \text { and }{ }^{\mathrm{g}} \mathrm{P}<0.001 \mathrm{vs} \text {. } \mathrm{DM}+\text { crush }+ \text { vehicle group. SFI was measured at baseline and after the crush injury } / \mathrm{sham} \text { surgery. } \\
\text { SFI, sciatic function index; } \mathrm{DM} \text {, diabetes mellitus; } A \text {. indica } 250 \text {, A. indica extract at a dose of } 250 \mathrm{mg} / \mathrm{kg} \text { animal body weight; } A \text {. indica } 500 \text {, } \\
\text { A. indica extract at a dose of } 500 \mathrm{mg} / \mathrm{kg} \text { animal body weight; A. indica } 750 ; \text { A. indica extract at a dose of } 750 \mathrm{mg} / \mathrm{kg} \text { animal body weight; } \\
\text { Vit } \mathrm{C} \text {, vitamin C; A. indica, Azadirachta indica. }\end{array}$} \\
\hline
\end{tabular}

Table II. Effect of A. indica flower extract on paw withdrawal latency.

\begin{tabular}{|c|c|c|c|c|}
\hline \multirow[b]{2}{*}{ Group } & \multicolumn{4}{|c|}{ Paw withdrawal latency, sec } \\
\hline & Baseline & Day 3 & Day 18 & Day 21 \\
\hline Control & $4.19 \pm 0.32$ & $4.38 \pm 0.20$ & $4.10 \pm 0.23$ & $4.48 \pm 0.27$ \\
\hline $\mathrm{DM}$ + sham + vehicle & $3.94 \pm 0.22$ & $4.61 \pm 0.23$ & $4.44 \pm 0.40$ & $4.11 \pm 0.41$ \\
\hline $\mathrm{DM}+$ crush + vehicle & $3.96 \pm 0.24$ & $15.54 \pm 0.98^{\mathrm{b}, \mathrm{d}}$ & $10.21 \pm 1.27^{\mathrm{a}, \mathrm{c}}$ & $9.83 \pm 1.39^{\mathrm{a}, \mathrm{c}}$ \\
\hline $\mathrm{DM}+$ crush + A. indica 250 & $4.04 \pm 0.23$ & $15.75 \pm 0.66^{\mathrm{b}, \mathrm{d}}$ & $10.00 \pm 1.92^{\mathrm{a}, \mathrm{c}}$ & $9.50 \pm 2.06^{\mathrm{a}, \mathrm{c}}$ \\
\hline $\mathrm{DM}+$ crush $+A$. indica 500 & $4.14 \pm 0.53$ & $15.29 \pm 0.99^{\mathrm{b}, \mathrm{d}}$ & $7.43 \pm 2.12$ & $7.24 \pm 1.59$ \\
\hline $\mathrm{DM}+$ crush $+A$. indica 750 & $4.00 \pm 0.24$ & $14.92 \pm 1.29^{\mathrm{b}, \mathrm{d}}$ & $6.58 \pm 0.66^{\mathrm{e}}$ & $5.75 \pm 0.56^{\mathrm{e}}$ \\
\hline $\mathrm{DM}+$ crush + Vit $\mathrm{C}$ & $4.14 \pm 0.26$ & $15.10 \pm 1.40^{\mathrm{b}, \mathrm{d}}$ & $7.38 \pm 1.00$ & $6.19 \pm 0.62^{\mathrm{e}}$ \\
\hline
\end{tabular}

Values are presented as the mean \pm standard error of the mean. ${ }^{a} \mathrm{P}<0.01$ and ${ }^{b} \mathrm{P}<0.001$ vs. the control; ${ }^{c} \mathrm{P}<0.01$ and ${ }^{\mathrm{d}} \mathrm{P}<0.001$ vs. the $\mathrm{DM}+$ sham + vehicle group; ${ }^{\mathrm{e}} \mathrm{P}<0.05$ vs. the $\mathrm{DM}+$ crush + vehicle group. Foot withdrawal reflex was measured at baseline and after the crush injury/sham surgery. DM, diabetes mellitus; A. indica 250, A. indica extract at a dose of $250 \mathrm{mg} / \mathrm{kg}$ animal body weight; A. indica 500, A. indica extract at a dose of $500 \mathrm{mg} / \mathrm{kg}$ animal body weight; A. indica $750 ; A$. indica extract at a dose of $750 \mathrm{mg} / \mathrm{kg}$ animal body weight; Vit C, vitamin C; A. indica, Azadirachta indica.

Effect of A.indica flower extract on sensory functional recovery. A hot plate test was used to assess the sensory function of rats and analyze PWL. The longer PWL indicates poor sensory function (31). The results of functional recovery, as determined by walking track analysis, foot withdrawal reflex and rotarod tests, were recorded on days 3,18 and 21 following sciatic nerve surgery (sham or crush; Tables I-III) as these results revealed significant changes. The effect of $A$. indica flower extract on PWL is presented in Table II. The results revealed that on day 3 , rats with sciatic nerve crush injury treated with vehicle exhibited a significantly longer PWL compared with the control group $(\mathrm{P}<0.001)$ and the vehicle group with sham operation $(\mathrm{P}<0.001)$. Moreover, the sciatic nerve crush injury groups exhibited a significantly longer PWL, as compared with the control group $(\mathrm{P}<0.001)$ and vehicle group with sham operation on day $3(\mathrm{P}<0.001)$. This indicated that a sciatic nerve crush significantly impaired sensory function.
Compared with the vehicle group with crush injury, the A. indica flower extract administered at a high dose $(750 \mathrm{mg} / \mathrm{kg}$ animal $\mathrm{BW})$ resulted in a significantly shorter PWL on postoperative day 18 and 21 (both $\mathrm{P}<0.05$ ) while the vitamin $\mathrm{C}$ group exhibited a significantly shorter PWL only on postoperative day $21(\mathrm{P}<0.05)$.

Effect of A. indica flower extract on sensorimotor coordination. The effect of $A$. indica flower extract on the mean falling latency is presented in Table III. Prior to the crush injury, rats were subjected to rotarod testing to determine the baseline falling latency. There was no significant difference in falling latency between the groups at baseline. The group of diabetic rats that received vehicle treatment and sham operation exhibited a decreased mean falling latency compared with the control group on day 3 following the crush injury; however, the difference was not statistically significant. Furthermore, 
Table III. Effect of A. indica flower extract on falling latency.

Falling latency, sec

\begin{tabular}{|c|c|c|c|c|}
\hline Group & Baseline & Day 3 & Day 18 & Day 21 \\
\hline Control & $16.00 \pm 1.75$ & $18.14 \pm 1.38$ & $24.00 \pm 2.54$ & $24.62 \pm 1.60$ \\
\hline $\mathrm{DM}+$ sham + vehicle & $17.22 \pm 1.57$ & $16.89 \pm 1.47$ & $22.28 \pm 3.08$ & $23.72 \pm 4.27$ \\
\hline $\mathrm{DM}+$ crush + vehicle & $16.58 \pm 1.98$ & $10.92 \pm 0.42^{\mathrm{c}, \mathrm{f}}$ & $17.29 \pm 1.79$ & $17.75 \pm 1.34^{\mathrm{a}}$ \\
\hline $\mathrm{DM}+$ crush + A. indica 250 & $16.46 \pm 1.54$ & $12.54 \pm 0.87^{\mathrm{c}, \mathrm{e}}$ & $21.75 \pm 3.78$ & $22.58 \pm 2.09$ \\
\hline $\mathrm{DM}+$ crush + A. indica 500 & $17.29 \pm 1.54$ & $12.10 \pm 0.80^{\mathrm{c}, \mathrm{e}}$ & $22.19 \pm 2.08$ & $23.05 \pm 2.43$ \\
\hline $\mathrm{DM}+$ crush + A. indica 750 & $17.17 \pm 2.44$ & $12.96 \pm 1.31^{\mathrm{b}, \mathrm{d}}$ & $22.67 \pm 1.59$ & $23.67 \pm 2.34$ \\
\hline $\mathrm{DM}+$ crush + Vit C & $16.19 \pm 0.71$ & $12.97 \pm 1.02^{\mathrm{b}, \mathrm{d}}$ & $20.67 \pm 3.75$ & $21.62 \pm 2.25$ \\
\hline
\end{tabular}

Values are presented as the mean \pm standard error of the mean. ${ }^{\mathrm{a}} \mathrm{P}<0.05,{ }^{\mathrm{b}} \mathrm{P}<0.01$ and ${ }^{\mathrm{c}} \mathrm{P}<0.001$ vs. the control; ${ }^{\mathrm{d}} \mathrm{P}<0.05,{ }^{\mathrm{e}} \mathrm{P}<0.01$ and ${ }^{\mathrm{f}} \mathrm{P}<0.001$ vs. the $\mathrm{DM}+$ sham + vehicle group. Rotarod test was measured at baseline and after the crush injury/sham surgery. DM, diabetes mellitus; A. indica 250, A. indica extract at a dose of $250 \mathrm{mg} / \mathrm{kg}$ animal body weight; A. indica 500 , A. indica extract at a dose of $500 \mathrm{mg} / \mathrm{kg}$ animal body weight; A. indica 750; A. indica extract at a dose of $750 \mathrm{mg} / \mathrm{kg}$ animal body weight; Vit C, vitamin C; A. indica, Azadirachta indica.

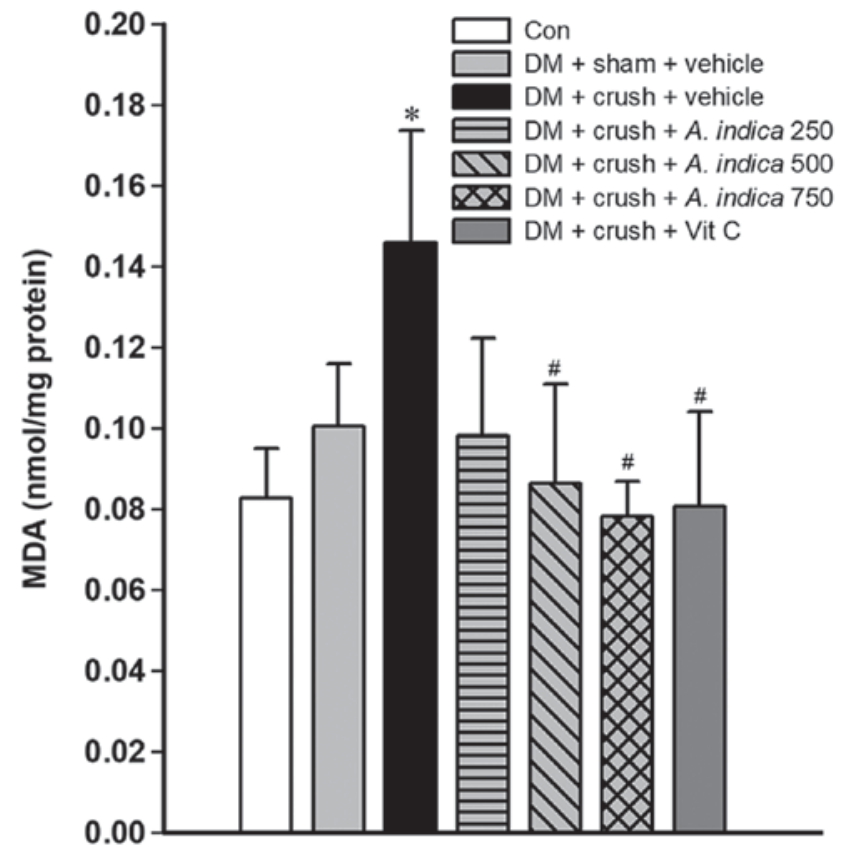

Figure 1. Effect of $A$. indica flower extract on the expression level of MDA in the sciatic nerve tissue homogenate. Values are expressed as the mean \pm standard error of the mean. ${ }^{*} \mathrm{P}<0.05$ vs. the con group; ${ }^{\#} \mathrm{P}<0.05$ vs. $\mathrm{DM}+$ crush + vehi cle group. MDA, malondialdehyde; Con, control; DM, diabetes mellitus; sham, sham surgery; crush, sciatic nerve crush surgery; A. indica 250, A. indica extract at a dose of $250 \mathrm{mg} / \mathrm{kg}$ animal body weight; $A$. indica $500, A$. indica extract at a dose of $500 \mathrm{mg} / \mathrm{kg}$ animal body weight; $A$. indica $750 ; A$. indica extract at a dose of $750 \mathrm{mg} / \mathrm{kg}$ animal body weight; Vit C, vitamin C.

the sciatic nerve crush injury groups exhibited a significantly shorter falling latency compared with the control group and vehicle group with sham operation on day 3 (all $\mathrm{P}<0.05)$. This suggests that a sciatic nerve crush significantly impaired sensorimotor coordination. In addition, compared with the vehicle group, the groups administered with A. indica flower extract at all doses exhibited an increase in the average falling latency. Nonetheless, there was no significant difference among the groups.

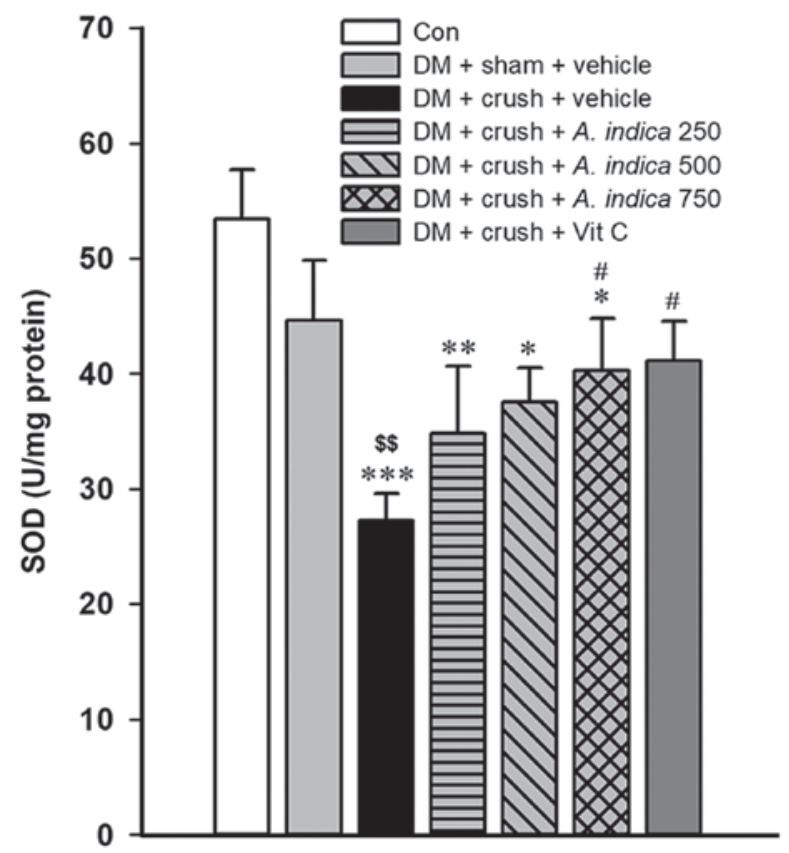

Figure 2. Effect of A. indica flower extract on the activity of SOD in the sciatic nerve tissue homogenate. Values are presented as the mean \pm standard error of the mean. ${ }^{*} \mathrm{P}<0.05,{ }^{* *} \mathrm{P}<0.01$ and ${ }^{* * *} \mathrm{P}<0.001$ vs. the con group; ${ }^{\$} \mathrm{P}<0.01$ vs. $\mathrm{DM}$ + sham + vehicle group; ${ }^{\#} \mathrm{P}<0.05$ vs. $\mathrm{DM}+$ crush + vehicle group. $\mathrm{SOD}$, superoxide dismutase; Con, control; DM, diabetes mellitus; sham, sham surgery; crush, sciatic nerve crush surgery; $A$. indica 250, $A$. indica extract at a dose of $250 \mathrm{mg} / \mathrm{kg}$ animal body weight; $A$. indica 500, A. indica extract at a dose of $500 \mathrm{mg} / \mathrm{kg}$ animal body weight; $A$. indica $750 ; A$. indica extract at a dose of $750 \mathrm{mg} / \mathrm{kg}$ animal body weight; Vit C, vitamin C.

Effect of A. indica flower extract on MDA levels. Oxidative stress is one of the most important mechanisms promoting nerve injury and delaying nerve recovery (32). The present study investigated the effect of the A. indica flower extract on MDA levels, an indicator of lipid peroxidation in injured sciatic nerve tissue (33) (Fig. 1). The diabetic rats in the sham surgery group exhibited increased MDA levels compared with the rats in the control group, however this difference was not statistically significant. Compared with the control group, 


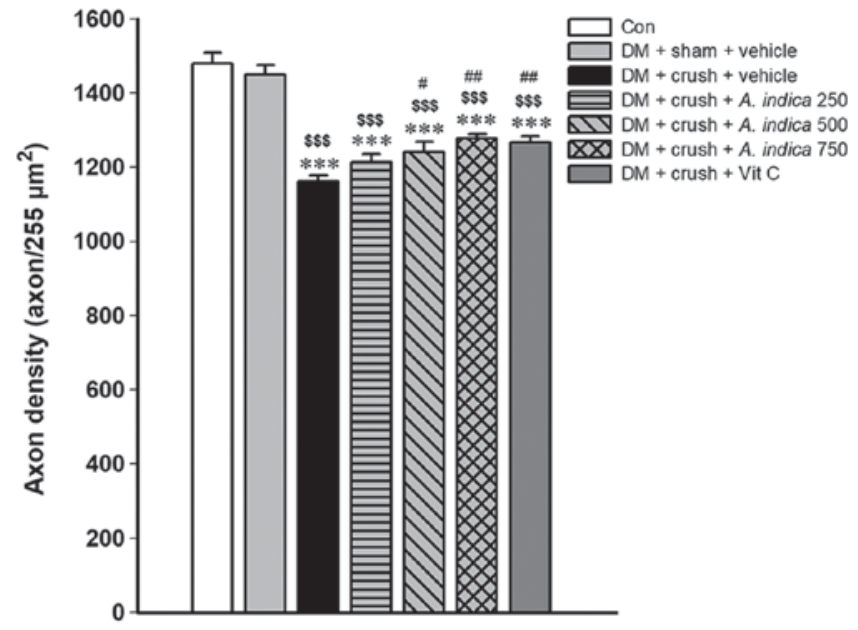

Figure 3. Effect of A. indica flower extract on the axon density of the sciatic nerve. Values are presented as the mean \pm standard error of the mean. ${ }_{* * * *} \mathrm{P}<0.001$ vs. the con group; ${ }^{\$ \$} \mathrm{P}<0.001$ vs. $\mathrm{DM}+$ sham + vehicle group; ${ }^{\#} \mathrm{P}<0.05$ and ${ }^{\# \#} \mathrm{P}<0.01$ vs. $\mathrm{DM}+$ crush + vehicle group. Con, control; DM, diabetes mellitus; sham, sham surgery; crush, sciatic nerve crush surgery; A. indica 250, A. indica extract at a dose of $250 \mathrm{mg} / \mathrm{kg}$ animal body weight; A. indica 500, A. indica extract at a dose of $500 \mathrm{mg} / \mathrm{kg}$ animal body weight; A. indica 750; A. indica extract at a dose of $750 \mathrm{mg} / \mathrm{kg}$ animal body weight; Vit C, vitamin C.

sciatic nerve crush injury increased the expression of MDA in the group with vehicle treatment and crush injury $(\mathrm{P}<0.05)$. Compared with the vehicle group with crush injury, the levels of MDA were significantly lower in rats treated with medium and high doses (500 and $750 \mathrm{mg} / \mathrm{kg}$ animal BW) of A. indica flower extract and group treated with vitamin $\mathrm{C}($ all $\mathrm{P}<0.05)$.

Effect of A. indica flower extract on SOD activity. SOD serves an important role in the free radical scavenging enzyme system (34). Therefore, the activity of SOD in sciatic nerve homogenate was determined. The results revealed that the rat models of DM treated with vehicle and subjected to the sciatic nerve crush injury demonstrated a significantly lower activity of SOD compared with both the control group and vehicle group subjected to sham operation $(\mathrm{P}<0.001$ and $\mathrm{P}<0.01$, respectively; Fig. 2). Rats with $\mathrm{DM}$ subjected to sham surgery and treated with vehicle exhibited a lower SOD activity compared with the rats in the control group, however, this difference was not statistically significant. Compared with the vehicle group with crush injury, the rats treated with a high dose $(750 \mathrm{mg} / \mathrm{kg}$ animal BW) of $A$. indica flower extract and rats treated with vitamin $C$ exhibited a significantly increased SOD activity (both $\mathrm{P}<0.05$ ).

Effect of A. indica flower extract on axon density. The functional recovery following a nerve injury is associated with the morphological change of the nerve. Therefore, the axon density of the nerve was evaluated to assess nerve regeneration. The effect of $A$. indica flower extract on axon density is presented in Fig. 3. The results indicated that the axon density of rat models of DM subjected to sham surgery was not significantly different compared with the control group. Compared with both the control group and rat models of DM subjected to sham surgery, the rats in the group subjected to a sciatic nerve crush injury exhibited a significantly lower axon density
$(\mathrm{P}<0.001$ and $\mathrm{P}<0.01$, respectively). Treatments with A. indica flower extract at medium and high doses $(500$ and $750 \mathrm{mg} / \mathrm{kg}$ animal BW) and vitamin $\mathrm{C}$ resulted in increased axon density compared with the vehicle group with crush injury $(\mathrm{P}<0.05$, $\mathrm{P}<0.01$ and $\mathrm{P}<0.01$, respectively).

\section{Discussion}

The present study demonstrated that treatment with $A$. indica flower extract for 21 days enhanced the functional recovery of a sciatic nerve crush injury in rats with STZ-induced DM. Additionally, the improvement of both sensory and motor functions was observed on day 18 after the crush injury. However, the full recovery of both motor and sensory function was not observed within 21 days.

Walking track analysis was used to determine the motor function of the rats. All rats exhibited normal motor function as manifested by normal SFI values (between -10 to 10) prior to the nerve injury. Compared with the control group, all groups of rats subjected to the crush injury exhibited lower SFI values indicating poor motor function. These values gradually improved over the 21-day period; however, recovery to pre-crush values was not observed in any group. The treatment with $A$. indica flower extract at a dose of $750 \mathrm{mg} / \mathrm{kg}$ animal BW improved SFI value at day 18 and 21 after the crush injury. However, the recovery was not complete as manifested by SFI values outside the normal range. In normal untreated rats, the full functional recovery of the sciatic nerve was observed at $\sim 14-21$ days after the crush injury $(35,36)$. Hadlock et al (37) reported that on postoperative day 34 , the recovery in normal untreated rats reached a plateau level and the pre-crush level was not reached. However, another study demonstrated that on day 21 after the crush injury, complete functional motor recovery was not observed in crocin treated rats (17). It has been suggested that nerve recovery of rats with DM was slower compared with normal healthy rats due to the pathophysiology of DM (38). A previous study demonstrated that hyperglycemia significantly lowered the rate of nerve recovery in rats with DM induced by STZ (6). Furthermore, one study indicated that in rats with DM induced by STZ, the motor functional recovery was not observed on postoperative day 21 (39), and these results were supported by the present study. However, different methods used to induce the nerve crush injury in previous studies (17,35-37,39), including the use of hemostatic forceps and Jewelers forceps, may have resulted in different magnitudes of the injury. Mazzer et al (40) further suggested that the different crushing loads can produce a different degree of axonotmesis injury. Therefore, the difference in motor functional recovery may be associated with the experimental conditions and the pathophysiological response of peripheral nerves to the level of different crushing loads and different methods to induce nerve injury.

Entrapment neuropathies are highly prevalent among patients with DM. Muscle weakness and poor sensation lead to the impairment of motor and sensory functions. The present study used a crush injury to induce sciatic nerve compression as this method induced mechanical pressure and ischemic injury to the nerve (41). The results of the present study support the conclusions of George et al (42). Specifically, the present study demonstrated that the crush injury significantly decreased the 
thermal sensitivity and induced hypoalgesia of the operated hind paw of rats with DM on day 3 after the crush injury (42). All groups of rats subjected to the crush injury exhibited hypoalgesia to the heat stimulus; however, this impairment improved over time. The recovery was not complete compared with normal rats; however, the rats with DM subjected to the crush injury that were administered a high dose $(750 \mathrm{mg} / \mathrm{kg}$ animal $\mathrm{BW}$ ) of $A$. indica flower extract exhibited a significant improvement in recovery from nociception deficit on postoperative day 18 and 21. Pavić et al (43) reported similar results with regard to sensory function 4 weeks following the crush. Furthermore, rats with DM subjected to sham operation presented the same response to the heat stimulus as observed among normal rats; however rats with DM and sciatic nerve crush injury presented hypoalgesia. This observation indicates that injection with STZ cannot induce sensory neuropathy in rats within 3 weeks following the injection. By contrast, a previous study demonstrated that diabetic ddY mice exhibited hypoalgesia when exposed to a mechanical nociceptor stimulus 5 weeks following induction of DM (44). In addition, mechanical hyposensitivity and the decreased motor nerve conduction velocity were developed at 6 and 8 weeks following induction of diabetes in another study (45). Prior research has demonstrated different responses to mechanical and thermal stimuli in rats with DM (46). The present study evaluated the response to the heat stimulus; however, the response to the mechanical stimulus remains to be elucidated. Therefore, future studies should investigate the response of rats with DM and sciatic nerve crush injury to different mechanical stimuli.

A rotarod test has been commonly used to test neurological deficits in experimental rodents, especially motor coordination and balance $(15,47)$. For example, a study by Mucimapura et al (15) used a rotarod test to determine sensorimotor coordination. The results of the present study indicated that rats with DM and sciatic nerve injury demonstrated a shorter falling latency compared with the normal rats. Administration with $A$. indica flower extract failed to improve sensorimotor coordination. Therefore, the functional recovery of sensory and motor functions demonstrated by the results of the walking track analysis and the heat withdrawal reflex test did not correspond with the results of the rotarod test. There may be other factors, including cardiopulmonary endurance, that influence the sensorimotor coordination of the rats. Jolivalt et al (48) suggested that the performance in the accelerating rotarod test was not affected by thermal hypoalgesia. However, the present study did not use the accelerating mode of the rotarod, as rats exhibited poor leg strength following crush injury. Furthermore, the large size of the rats meant that they fitted tightly in the rotarod compartment and previous studies have demonstrated a significant correlation between high body weight and low rotarod performance $(49,50)$. In addition, the low height of the rod from the base was also reported to influence the mice to jump off the apparatus (51). Therefore, these factors may have influenced the results.

Several studies demonstrated that individuals with DM tend to exhibit increased levels of reactive oxygen species and oxidative stress markers, with an accompanying decrease in antioxidant levels (52-54). In addition, previous studies indicated that oxidative stress serves a role in nerve destruction following injury (17,55). Furthermore, it has been demonstrated that antioxidants serve important roles in nerve recovery $(56,57)$. MDA is an oxidative stress marker (58), while SOD is an antioxidative enzyme that detoxifies superoxide anions (59). Reduced activity of SOD increases the generation of reactive oxygen species leading to the damage of cellular organelles and increased lipid peroxidation (13). These consequences of oxidative stress can further aggravate the complications associated with DM (60). A previous study indicated that SOD was inactivated by glycation (61). Another study reported that SOD activity was decreased in STZ-induced rat models of DM (62). An injection with STZ was reported to increase MDA levels and decrease the activity of SOD in rats with DM $(63,64)$. The results of the present study indicated that the rats with DM and sham surgery exhibited increased MDA levels and decreased SOD activity compared with rats in the control group. However, this difference was not statistically significant. This result indicates that the STZ injection may not be the only factor affecting the oxidative stress in the sciatic nerve tissue of rats with DM. Previous studies demonstrated that crush injury induced an increase in the oxidative stress of rats with STZ-induced DM $(65,66)$. The present results demonstrated that rats with DM subjected to sciatic nerve crush injury and treated with vehicle demonstrated elevated levels of MDA. This result indicated that sciatic nerve crush injury, used as a model of nerve compression syndrome, induced oxidative stress in rats with DM. Administration of the A. indica flower extract significantly decreased MDA levels and increased the activity of SOD in the sciatic nerve homogenate. The same observations were made among rats treated with vitamin $C$. Therefore, these results suggested that $A$. indica flower extract may improve functional recovery by decreasing the oxidative stress and increasing antioxidative enzyme activity. However, the alteration of other parameters involved in the oxidative stress pathway should be further investigated.

Crush injury has previously been used to model axonotmesis injury (67). This model is widely used to evaluate peripheral nerve regeneration $(34,68)$. Crush injury damages the axons covered with the supporting structures, including endoneurium, perineurium and epineurium, resulting in secondary Wallerian degeneration distal to the site of injury (69). A previous study demonstrated that crushing load significantly reduced the density of nerve fibers (39). The results of the present study indicated that there was no statistically significant difference in myelinated axon density between rats with DM subjected to sham operation and rats in the control group. By contrast, 21 days following the crush injury, the crush group exhibited significantly lower myelinated axon density compared with the vehicle group with sham injury. Administration of A. indica flower extract at dose of 500 and $750 \mathrm{mg} / \mathrm{kg}$ animal BW induced a significant increase in axon density compared with the vehicle treatment. Tong et al (70) reported that functional recovery following sciatic nerve crush injury was associated with remyelination rather than axon regeneration. Therefore, the $A$. indica flower extract may accelerate the remyelination process leading to an increased density of nerve fibers. Nevertheless, electrophysiological, morphological and histological studies should be performed to assess peripheral nerve recovery fully. However, due to the limited availability of laboratory equipment, the present study only observed histological alterations using H\&E staining. 
Therefore, future studies with the aforementioned additional techniques should examine nerve recovery in further detail.

The results of the present study indicated that high and medium doses of flower extract were more effective compared with low doses in certain experiments. Treatment with the A. indica flower extract at medium and high doses (500 and $750 \mathrm{mg} / \mathrm{kg}$ animal BW, respectively) significantly improved motor and sensory functional recovery. This may be due to the higher concentration of active ingredients in the higher doses of the extract. The primary constituent identified in the flower extract was quercetin, as reported previously by Duangjai et al (71). This result was congruent with a previous study, which indicated that rutin and quercetin flavonoids were the primary antioxidative components in A. indica flowers (19). Quercetin was reported to significantly improve the functional recovery of the sciatic nerve following crush injury in C57BL/6J mice (57) and STZ-induced rat models of DM (39). Quercetin facilitates nerve recovery by increasing the density of myelinated axons (72). Therefore, quercetin may be the active component which promoted the functional recovery of the sciatic nerve following the crush injury induced in the present study.

In conclusion, the results of the present study indicated that $A$. indica flower extract accelerated the functional recovery of sciatic nerve injury in rat models of DM. It may be hypothesized that the recovery was associated with the antioxidative effects induced by the flower extract. These results may be beneficial for the application of alternative treatments for patients with DM and nerve injury. Nevertheless, additional studies are required to specify the time required to attain complete functional recovery and clarify the underlying mechanisms of treatment with the flower extract.

\section{Acknowledgements}

The authors would like to thank DrPennapa Chonpathompikunlert from the Expert Centre of Innovative Health Food, Thailand Institute of Scientific and Technological Research, Khlong Luang, Pathum Thani for additional chemical support. Thanks are also given to Mr. Theera Chanmanee and Mr. Panumat Deiam from the Division of Anatomy, School of Medical Sciences, University of Phayao for histological assessment. Finally, the authors wish to commend the Division of Research Administration and Educational Quality Assurance, University of Phayao for managing the grant and the University of Phayao for providing research facilities.

\section{Funding}

The present study was financially supported by the University of Phayao, Mueang, Phayao, Thailand (grant no. RD59052)

\section{Availability of data and materials}

Datasets used and/or analyzed during the present study are available from the corresponding author on reasonable request.

\section{Authors' contributions}

NS conceived and designed the present study and analyzed the data. NS, RK, AD, TH and ST performed the experiments.
NS and TH prepared the manuscript. All authors read and approved the final manuscript prior to submission.

\section{Ethics approval and consent to participate}

All experiments were approved by the Ethics Committee of the Laboratory Animal Research Center, University of Phayao (approval no. 5801040035 ).

\section{Patient consent for publication}

Not applicable.

\section{Competing interests}

The authors declare that they have no competing interests.

\section{References}

1. Strategy and Planning Division, Ministry of Public Health, Thailand: Summary report of illness 2016. Available from: http:// bps.moph.go.th/new_bps/sites/default/files/ill_2559_full_edit.pdf. Accessed December 25, 2017.

2. Schofield D, Cunich MM, Shrestha RN, Passey ME, Veerman L, Callander EJ, Kelly SJ and Tanton R: The economic impact of diabetes through lost labour force participation on individuals and government: Evidence from a microsimulation model. BMC Public Health 14: 220, 2014.

3. Vinik A, Mehrabyan A, Colen L and Boulton A: Focal entrapment neuropathies in diabetes. Diabetes Care 27: 1783-1788, 2004.

4. Kim HJ and Park SH: Median nerve injuries caused by carpal tunnel injections. Korean J Pain 27: 112-117, 2014.

5. Kerezoudis P, Rinaldo L, Alvi MA, Hunt CL, Qu W, Maus TP and Bydon M: The effect of epidural steroid injections on bone mineral density and vertebral fracture risk: A systematic review and critical appraisal of current literature. Pain Med 19: 569-579, 2018.

6. Wang PH, Yang CC, Su WR, Wu PT, Cheng SC and Jou IM: Effects of decompression on behavioral, electrophysiologic, and histomorphologic recovery in a chronic sciatic nerve compression model of streptozotocin-induced diabetic rats. J Pain Res 10: 643-652, 2017.

7. Sessions J and Nickerson DS: Biologic basis of nerve decompression surgery for focal entrapments in diabetic peripheral neuropathy. J Diabetes Sci Technol 8: 412-418, 2014.

8. Tomlinson DR and Gardiner NJ: Glucose neurotoxicity. Nat Rev Neurosci 9: 36-45, 2008.

9. Negre-Salvayre A, Salvayre R, Augé N, Pamplona R and Portero-Otín M: Hyperglycemia and glycation in diabetic complications. Antioxid Redox Signal 11: 3071-3109, 2009.

10. Chen RJ, Lin CC and Ju MS: In situ biomechanical properties of normal and diabetic nerves: An efficient quasi-linear viscoelastic approach. J Biomech 43: 1118-1124, 2010.

11. Shimizu F, Sano Y, Haruki H and Kanda T: Advanced glycation end-products induce basement membrane hypertrophy in endoneurial microvessels and disrupt the blood-nerve barrier by stimulating the release of TGF- $\beta$ and vascular endothelial growth factor (VEGF) by pericytes. Diabetologia 54: 1517-1526, 2011.

12. Ohno N, Kidd GJ, Mahad D, Kiryu-Seo S, Avishai A, Komuro H and Trapp BD: Myelination and axonal electrical activity modulate the distribution and motility of mitochondria at CNS nodes of Ranvier. J Neurosci 31: 7249-7258, 2011.

13. Rains JL and Jain SK: Oxidative stress, insulin signaling, and diabetes. Free Radic Biol Med 50: 567-575, 2011.

14. He L, He T, Farrar S, Ji L, Liu T and Ma X: Antioxidants maintain cellular redox homeostasis by elimination of reactive oxygen species. Cell Physiol Biochem 44: 532-553, 2017.

15. MucimapuraS, Wattanathorn J, Thongrong S, Chaisiwamongkol K and Sripanidkulchai B: Morus alba enhanced functional recovery after sciatic nerve crush injury. Am J Agric Biol Sci 5: 294-300, 2010.

16. Thipkaew C, Wattanathorn J and Muchimapura S: The beneficial effect of asiaticoside on experimental neuropathy in diabetic rats. Am J Appl Sci 9: 1782-1788, 2012. 
17. Tamaddonfard E, Farshid AA, Ahmadian E and Hamidhoseyni A Crocin enhanced functional recovery after sciatic nerve crush injury in rats. Iran J Basic Med Sci 16: 83-90, 2013.

18. Subapriya $R$ and Nagini S: Medicinal properties of neem leaves: A review. Curr Med Chem Anticancer Agents 5: 149-6, 2005.

19. Chaisawangwong W and Gritsanapan W: Quality assessment and scavenging activity of Siamese neem flower extract. Nat Prod Res 27: 394-401, 2013.

20. Sultana B, Anwar F and Przybylski R: Antioxidant activity of phenolic components present in barks of Azadirachta indica, Terminalia arjuna, Acacia nilotica, and Eugenia jambolana Lam. trees. Food Chem 104: 1106-1114, 2007.

21. Jagadeesh K, Srinivas K and Revankar SP: Anti inflammatory effect of Azadirachta Indica (Neem) in albino rats: An experimental study. IOSR J Pharm 4: 34-38, 2014.

22. Bhajoni PS, Meshram GG and Lahkar M: Evaluation of the antiulcer activity of the leaves of Azadirachta indica: An experimental study. Integr Med Int 3: 10-16, 2016.

23. Hao F, Kumar S, Yadav N and Chandra D: Neem components as potential agents for cancer prevention and treatment. Biochim Biophys Acta 1846: 247-257, 2014

24. Bhat M, Kothiwale SK, Tirmale AR, Bhargava SY and Joshi BN: Antidiabetic properties of Azadirachta indica and Bougainvillea spectabilis: In vivo studies in murine diabetes model. Evid Based Complement Alternat Med 2011: 561625, 2011.

25. Bain JR, Mackinnon SE and Hunter DA: Functional evaluation of complete sciatic, peroneal, and posterior tibial nerve lesions in the rat. Plast Reconstr Surg 83: 129-138, 1989.

26. Menéndez L, Lastra A, Hidalgo A and Baamonde A: Unilateral hot plate test: A simple and sensitive method for detecting centra and peripheral hyperalgesia in mice. J Neurosci Methods 113 91-97, 2002.

27. Bohlen M, Cameron A, Metten P, Crabbe JC and Wahlsten D: Calibration of rotational acceleration for the rotarod test of rodent motor coordination. J Neurosci Methods 178: 10-14, 2009

28. Abada YS, Nguyen HP, Schreiber R and Ellenbroek B: Assessment of motor function, sensory motor gating and recognition memory in a novel BACHD transgenic rat model for huntington disease. PLoS One 8: e68584, 2013.

29. Ohkawa H, Ohishi $\mathrm{N}$ and Yagi K: Assay for lipid peroxides in animal tissues by thiobarbituric acid reaction. Anal Biochem 95 351-358, 1979 .

30. Wattanathorn J, Thiraphatthanavong P, Muchimapura S, Thukhammee W, Lertrat K and Suriharn B: The combined extract of Zingiber officinale and Zea mays (Purple Color) improves neuropathy, oxidative stress, and axon density in streptozotocin induced diabetic rats. Evid Based Complement Alternat Med 2015: 301029, 2015.

31. Lennertz RC, Medler KA, Bain JL, Wright DE and Stucky CL: Impaired sensory nerve function and axon morphology in mice with diabetic neuropathy. J Neurophysiol 106: 905-914, 2011.

32. Vincent AM, Russell JW, Low P and Feldman EL: Oxidative stress in the pathogenesis of diabetic neuropathy. Endocr Rev 25 612-628, 2004

33. Aziza SAH, El-Haggar M, Abo-Zaid OA, Hassanien MR and El-Shawarby R: Biomarkers of oxidative stress of sciatic nerve tissues in experimental diabetic neuropathy. J Med Sci 14: 12-20, 2014.

34. Senoglu M, Nacitarhan V, Kurutas EB, Senoglu N, Altun I, Atli Y and Ozbag D: Intraperitoneal Alpha-Lipoic Acid to prevent neural damage after crush injury to the rat sciatic nerve. J Brachial Plex Peripher Nerve Inj 4: 22, 2009.

35. Ramli D, Aziz I, Mohamad M, Abdulahi D and Sanusi J: The changes in rats with sciatic nerve crush injury supplemented with evening primrose oil: Behavioural, Morphologic, and Morphometric Analysis. Evid Based Complement Alternat Med 2017: 3476407, 2017

36. Xavier AM, Serafim KG, Higashi DT, Vanat N, Flaiban KK, Siqueira CP, Venâncio EJ and Ramos SP: Simvastatin improves morphological and functional recovery of sciatic nerve injury in Wistar rats. Injury 43: 284-289, 2012.

37. Hadlock TA, Heaton J, Cheney M and Mackinnon SE: Functional recovery after facial and sciatic nerve crush injury in the rat. Arch Facial Plast Surg 7: 17-20, 2005.

38. Kennedy JM and Zochodne DW: Impaired peripheral nerve regeneration in diabetes mellitus. J Peripher Nerv Syst 10: 144-157, 2005.

39. Thipkaew C, Wattanathorn J and Muchimapura S: Electrospun nanofibers loaded with quercetin promote the recovery of focal entrapment neuropathy in a rat model of streptozotocin-induced diabetes. BioMed Res Int 2017: 2017493, 2017.
40. Mazzer PY, Barbieri CH, Mazzer N and Fazan VP: Morphologic and morphometric evaluation of experimental acute crush injuries of the sciatic nerve of rats. J Neurosci Methods 173: 249-258, 2008

41. Gao Y, Weng C and Wang X: Changes in nerve microcirculation following peripheral nerve compression. Neural Regen Res 8: 1041-1047, 2013

42. George A, Buehl A and Sommer C: Wallerian degeneration after crush injury of rat sciatic nerve increases endo- and epineurial tumor necrosis factor-alpha protein. Neurosci Lett 372: 215-219, 2004.

43. Pavić R, Pavić ML, Tvrdeić A, Tot OK and Heffer M: Rat sciatic nerve crush injury and recovery tracked by plantar test and immunohistochemistry analysis. Coll Antropol 35 (Suppl 1): 93-100, 2011.

44. Murakami T, Iwanaga T, Ogawa Y, Fujita Y, Sato E, Yoshitomi H, Sunada Y and Nakamura A: Development of sensory neuropathy in streptozotocin-induced diabetic mice. Brain Behav 3: 35-41, 2013.

45. Kambiz S, van Neck JW, Cosgun SG, van Velzen MH, Janssen JA, Avazverdi N, Hovius SE and Walbeehm ET: An early diagnostic tool for diabetic peripheral neuropathy in rats. PLoS One 10: e0126892, 2015.

46. Brussee V, Guo G, Dong Y, Cheng C, Martinez JA, Smith D, Glazner GW, Fernyhough P and Zochodne DW: Distal degenerative sensory neuropathy in a long-term type 2 diabetes rat model. Diabetes 57: 1664-1673,2008.

47. Carter RJ, Morton J and Dunnett SB: Motor coordination and balance in rodents. Curr Protoc Neurosci: Aug 1, 2001 (Epub ahead of print). doi: 10.1002/0471142301.ns0812s15.

48. Jolivalt CG, Rodriguez M, Wahren J and Calcutt NA: Efficacy of a long-acting C-peptide analogue against peripheral neuropathy in streptozotocin-diabetic mice. Diabetes Obes Metab 17: 781-788, 2015.

49. McFadyen MP, Kusek G, Bolivar VJ and Flaherty L: Differences among eight inbred strains of mice in motor ability and motor learning on a rotorod. Genes Brain Behav 2: 214-219, 2003.

50. Cook MN, Bolivar VJ, McFadyen MP and Flaherty L: Behavioral differences among 129 substrains: Implications for knockout and transgenic mice. Behav Neurosci 116: 600-611, 2002.

51. Deacon RM: Measuring motor coordination in mice. J Vis Exp 75: e2609, 2013.

52. Sharma R, Buras E, Terashima T, Serrano F, Massaad CA, Hu L, Bitner B, Inoue T, Chan L and Pautler RG: Hyperglycemia induces oxidative stress and impairs axonal transport rates in mice. PLoS One 5: e13463, 2010

53. Murali R, Karthikeyan A and Saravanan R: Protective effects of D-limonene on lipid peroxidation and antioxidant enzymes in streptozotocin-induced diabetic rats. Basic Clin Pharmacol Toxicol 112: 175-181, 2013

54. Babizhayev MA, Strokov IA, Nosikov VV, Savel'yeva EL, Sitnikov VF, Yegorov YE and Lankin VZ: The role of oxidative stress in diabetic neuropathy: Generation of free radical species in the glycation reaction and gene polymorphisms encoding antioxidant enzymes to genetic susceptibility to diabetic neuropathy in population of type I diabetic patients. Cell Biochem Biophys 71: 1425-1443, 2015

55. Serarslan Y, Bal R, Altug ME, Kontaş T, Keleş ON, Unal D and Unal B: Effects of trimetazidine on crush injury of the sciatic nerve in rats: A biochemical and stereological study. Brain Res 1247: 11-20, 2009.

56. Lanza C, Raimondo S, Vergani L, Catena N, Sénès F, Tos $P$ and Geuna S: Expression of antioxidant molecules after peripheral nerve injury and regeneration. J Neurosci Res 90: 842-848, 2012.

57. Chen MM, Qin J, Chen SJ, Yao LM, Zhang LY, Yin ZQ and Liao H: Quercetin promotes motor and sensory function recovery following sciatic nerve-crush injury in C57BL/6J mice. J Nutr Biochem 46: 57-67, 2017.

58. Yoshida Y, Umeno A and Shichiri M: Lipid peroxidation biomarkers for evaluating oxidative stress and assessing antioxidant capacity in vivo. J Clin Biochem Nutr 52: 9-16, 2013

59. Fridovich I: Superoxide radical and superoxide dismutases. Annu Rev Biochem 64: 97-112, 1995

60. Giacco F and Brownlee M: Oxidative stress and diabetic complications. Circ Res 107: 1058-1070, 2010.

61. Jabeen R, Saleemuddin M, Petersen J and Mohammad A: Inactivation and modification of superoxide dismutase by glyoxal: Prevention by antibodies. Biochimie 89: 311-318, 2007.

62. Sadri H, Goodarzi MT, Salemi Z and Seifi M: Antioxidant effects of Biochanin A in streptozotocin induced diabetic rats. Braz Arch Biol Technol 60: e1716074, 2017. 
63. Aizzat O, Yap SW, Sopiah H, Madiha MM, Hazreen M, Shailah A Wan JW, Nur SA, Srijit D, Musalmah M, et al: Modulation of oxidative stress by Chlorella vulgaris in streptozotocin (STZ) induced diabetic Sprague-Dawley rats. Adv Med Sci 55: 281-288, 2010.

64. Sellamuthu PS, Arulselvan P, Kamalraj S, Fakurazi S and Kandasamy M: Protective nature of mangiferin on oxidative stress and antioxidant status in tissues of streptozotocin-induced diabetic rats. ISRN Pharmacol 2013: 750109, 2013.

65. Farshid AA and Tamaddonfard E: Histopathological and behavioral evaluations of the effects of crocin, safranal and insulin on diabetic peripheral neuropathy in rats. Avicenna J Phytomed 5: 469-478, 2015.

66. Nasiry D, Khalatbary AR, Ahmadvand H, Talebpour Amiri F and Akbari E: Protective effects of methanolic extract of Juglans regia $\mathrm{L}$. leaf on streptozotocin-induced diabetic peripheral neuropathy in rats. BMC Complement Altern Med 17: 476, 2017.

67. Magill CK, Tong A, Kawamura D, Hayashi A, Hunter DA Parsadanian A, Mackinnon SE and Myckatyn TM: Reinnervation of the tibialis anterior following sciatic nerve crush injury: A confocal microscopic study in transgenic mice. Exp Neurol 207: 64-74, 2007.
68. Gao S, Fei M, Cheng C, Yu X, Chen M, Shi S, Qin J, Guo Z and Shen A: Spatiotemporal expression of PSD-95 and nNOS after rat sciatic nerve injury. Neurochem Res 33: 1090-1100, 2008.

69. Sunderland S: A classification of peripheral nerve injuries producing loss of function. Brain 74: 491-516, 1951.

70. Tong LL, Ding YQ, Jing HB, Li XY and Qi JG: Differential motor and sensory functional recovery in male but not female adult rats is associated with remyelination rather than axon regeneration after sciatic nerve crush. Neuroreport 26: 429-437, 2015.

71. Duangjai A, Nuengchamnong N, Lee LH, Goh BH, Saokaew S and Suphrom N: Characterisation of an extract and fractions of Azadirachta indica flower on cholesterol lowering property and intestinal motility. Nat Prod Res 19: 1-4, 2017.

72. Wang W, Huang CY, Tsai FJ, Tsai CC, Yao CH and Chen YS: Growth-promoting effects of quercetin on peripheral nerves in rats. Int J Artif Organs 34: 1095-1105, 2011. 